\title{
WNT7B in fibroblastic foci of idiopathic pulmonary fibrosis
}

\author{
Travis Meuten ${ }^{1}$, Ariel Hickey ${ }^{1}$, Katherine Franklin ${ }^{1}$, Brian Grossi $^{1}$, Jeremy Tobias ${ }^{2}$, Donna R Newman', \\ Samuel $\mathrm{H}$ Jennings ${ }^{1}$, Maria Correa ${ }^{2}$ and Philip L Sannes ${ }^{1 *}$
}

\begin{abstract}
Background: Idiopathic pulmonary fibrosis (IPF) is a devastating interstitial pneumonia causing a loss of respiratory surface area due to a proliferative fibrotic response involving hyperplastic, hypertrophic, and metaplastic epithelium, cystic honeycomb change, septal expansion, and variable inflammation. Wnt (wingless) signaling glycoproteins are known to be involved in lung development and tissue repair, and are up-regulated in patients with IPF. Based on previous qRT-PCR data showing increased Wnt7B in lungs of IPF patients, a systematic, quantitative examination of its tissue site distribution was undertaken.
\end{abstract}

Methods: Tissue samples from the Lung Tissue Research Consortium (LTRC) of 39 patients diagnosed with mild to severe IPF/usual interstitial pneumonia (UIP) and 19 normal patients were examined for the immunolocalization of Wnt7B.

Results: In normal lung, moderate Wnt7B reactivity was confined to airway epithelium, smooth muscle of airways and vasculature, and macrophages. IPF lung showed strong Wnt7B reactivity in fibroblastic foci, dysplastic airway and alveolar epithelium, and in highly discrete subepithelial, basement membrane-associated regions. All reactive sites were sized and counted relative to specific microscopic regions. Those in the subepithelial sites were found in significantly greater numbers and larger relative area compared with the others. No reactive sites were present in normal patient controls.

Conclusions: The results demonstrate Wnt7B to be expressed at high concentrations in regions of active hyperplasia, metaplasia, and fibrotic change in IPF patients. In this context and its previously established biologic activities, Wnt7B would be expected to be of potential importance in the pathogenesis of IPF.

Keywords: Myofibroblasts, Alveolar epithelium, Interstitial lung disease

\section{Introduction}

Idiopathic pulmonary fibrosis/usual interstitial pneumonia (IPF/UIP) is a debilitating disease characterized by a loss of normal respiratory architecture and replacement with a heterogeneous population of myofibroblast-like cells and excess of fibrous connective tissue restricted to the lung [1,2]. IPF arises from inflammation in the alveolar-capillary wall resulting in alveolar type I cell (AT1) loss and AT2 cell hyperplasia and subepithelial/ interstitial fibrogenesis [3,4]. It has been suggested this represents an attempt to repair the pulmonary barrier

\footnotetext{
*Correspondence: philip_sannes@ncsu.edu

'Departments of Molecular Biomedical Sciences, College of Veterinary Medicine, North Carolina State University, 1060 William Moore Dr, Raleigh, NC 27607, USA

Full list of author information is available at the end of the article
}

following an injury to the respiratory surface [5]. The hallmark lesions are fibroblastic foci, signifying active disease, with a patchy mix of older fibrosis starting from the subpleural surface and along interlobular septa. Early lesions frequently appear highly cellular, with subepithelial fibroblastic foci adjacent to normal pulmonary architecture [6,7]. In IPF the lesions lead to end-stage fibrosis with minimal remaining pulmonary structure [6-8]. The proposed pathogenesis centers on dysregulation of epithelial repair in the form of hyperplastic and metaplastic AT2 cells interrelated with fibroproliferative lesions and aberrant epithelial differentiation, including epithelial to mesenchymal transition (EMT) [8,9].

The signaling pathways involved are only partially understood. It is known that there is increased

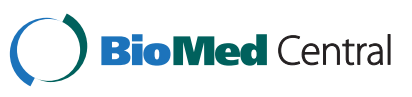


expression of TGF- $\beta$ and $\alpha$-smooth muscle actin $(\alpha-S M A)$ in progressive lesions of IPF reflecting the transition of fibroblasts to myofibroblasts with proliferation and collagen maintenance modulated by wingless (Wnt) glycoproteins [10-12]. Mouse models indicate cooperation of TGF- $\beta$ and Wnt signaling pathways in development, differentiation, and EMT [13]. Altered expression of Wnt ligands and one of their downstream targets, $\beta$ catenin, is evident in early IPF and bleomycin models of pulmonary fibrosis [14-16]. This can be explained in light of up-regulated TGF- $\beta$ by its induction of LEF-1, which is a component of the canonical Wnt signaling pathway [13]. Chilosi, et al., found highly concentrated sites of $\beta$-catenin in myofibroblast-populated regions adjacent to airways [14]. This correlated with elevated mRNA expression and immunohistochemical reactivity of Wnts 1 \& 3a in adjacent pulmonary epithelium in IPF patients [17]. Recent evidence shows that Wnt3a can activate $\beta$-catenin-mediated signaling and induce EMT in lung epithelial cells [18]. The collective views suggest that canonical Wnt signaling ( $\beta$-catenin mediated) is upregulated in fibrogenic conditions and may be causally involved in IPF [16-19].

Wnt glycoproteins have been found to be expressed at low levels in the normal lung and may be associated with epithelial turnover $[17,20]$. For example, Wnt7B mRNA expression in isolated normal AT2 cells was evident in low levels [17,21]. Wnt7b over-expression is thought to be a contributing factor to fibrogenesis in the murine kidney [22] and to be involved with procollagen production by lung fibroblasts [12]. Wnt7b was of special interest because of its role in mesenchymal proliferation and vascular development in the lung [23]. Based on supporting qRT-PCR data showing increased Wnt7B in lungs of IPF patients [17], a systematic, examination of its localization in a cohort of 39 IPF lungs was undertaken. Wnt7B expression was found in spindle cells and extracellular matrix of virtually all fibroblastic foci and in widely distributed, large numbers of discretely defined regions of the subepithelial basement membrane zone. These findings may provide useful clues relating to the pathogenesis of IPF and present novel, potential targets for detection and treatment.

\section{Materials \& methods Immunostaining}

Tissue blocks of formalin-fixed lung tissue samples were obtained from the Lung Tissue Research Consortium (LTRC). The samples had previously been placed into three groups (see Table 1): group 1, with forced vital capacities (FVCs) $>80 \%$ (normal, or no specified major or minor diagnosis, $\mathrm{n}=19$ ); group 2, with FVCs between $50-80 \%$ [major final clinical diagnosis as interstitial lung disease (ILD, $n=20$ ) and minor final clinical diagnosis as usual interstitial pneumonia (UIP)/idiopathic pulmonary fibrosis (IPF)]; and group 3, with FVCs $<50 \%$ (major final clinical diagnosis of ILD and minor final clinical diagnosis as UIP/IPF, $\mathrm{n}=19$ ). No other patient identifiers were provided, and their anonymity and confidentiality were preserved. The study was approved by the North Carolina State University Institutional Review Board. Blocks were further randomized and sections stained with hematoxylin and eosin (H\&E) and picrosirius red (PSR) or Movat's pentachrome stain for collagen. H\&E sections were examined by a Board Certified Pathologist to independently confirm/reclassify initial clinical diagnoses.

Sections were treated with citrate buffer for antigen retrieval and treated with a polyclonal goat anti-Wnt7B antibody [Santa Cruz Biotechnology, Inc. (sc26363, lot\# I0205, Santa Cruz, CA)] at a 1:100 dilution overnight at $4^{\circ} \mathrm{C}$, followed by peroxidase-labeled secondary antibodies (Dako LSAB+, Dako Laboratories, Carpinteria, CA) and Nova Red (Vector Laboratories, Burlingame, CA). The Wnt7B antibody recognizes both precursor and mature forms of human origin. Control samples substituted normal goat serum for the primary antibody, or were pre-treated with $5 \%$ testicular hyaluronidase (Sigma, Type 1-S, St. Louis, MO) for 30 minutes at $37^{\circ} \mathrm{C}$ to release Wnt7B bound to extracellular matrices [24], or treated with a competitive antibody-binding Wnt7B peptide to the primary antibody incubation. Sections were counterstained with methylene blue. Selected sequential and non-sequential serial sections were immunostained with anti-human smooth muscle actin.

\section{Analysis of Reactive Sites}

The entirety of each section was systematically evaluated at 200X magnification through a calibrated ocular grid, and the size of each $\mathrm{Wnt7B}$ reactive site was measured. They were divided into three major size categories: $<50 \mu \mathrm{m}^{2}, 50-100 \mu \mathrm{m}^{2}$, and $>100 \mu \mathrm{m}^{2}$; while their histologic sites were separated into one of three regional designations: 1) epithelium and underlying fibroblasts with or without extracellular matrix (EF), 2) subepithelial fibroblasts and ECM (SE) without epithelial staining (included most fibroblastic foci), and 3) interstitial fibroblasts and ECM (I) that were not directly subjacent to an epithelial surface. The number of sites corresponding to the respective categories was recorded. The total surface area, as defined by the external border of each tissue section, was determined using ImageJ (National Institutes of Health, Bethesda, MD), and the percent of the total area of each reactive site category relative to the total section surface area was calculated (see Table 1). 
Table 1 Patient group data summary and total Wnt7B area reactivity

\begin{tabular}{|c|c|c|c|c|c|c|c|c|}
\hline Patient ID & $\begin{array}{l}\text { Area Total } \\
\mu \mathrm{m}^{2} / \mathrm{mm}^{2}\end{array}$ & $\begin{array}{l}\text { Path Diagnosis } \\
\text { FVC }>\mathbf{8 0} \%\end{array}$ & Patient ID & $\begin{array}{l}\text { Area Total } \\
\mu \mathrm{m}^{2} / \mathrm{mm}^{2}\end{array}$ & $\begin{array}{c}\text { Path Diagnosis } \\
\text { FVC }>\mathbf{5 0 \%}<\mathbf{8 0 \%}\end{array}$ & Patient ID & $\begin{array}{l}\text { Area Total } \\
\mu \mathrm{m}^{2} / \mathrm{mm}^{2}\end{array}$ & $\begin{array}{l}\text { Path Diagnosis } \\
\text { FVC }<\mathbf{5 0 \%}\end{array}$ \\
\hline $34 / 1$ & 0 & Normal & $22 / 29$ & 0.22660864 & Mild IF & $53 / 13$ & 0.308239253 & Mild IF \\
\hline $50 / 8$ & 0 & Normal & $52 / 59$ & 0.46500093 & Mild IF & $40 / 11$ & 0.318122907 & Mild IF \\
\hline $60 / 9$ & 0 & Normal & $9 / 55$ & 0.702668072 & IPF & $51 / 7$ & 0.421600843 & IPF/UIP \\
\hline $29 / 25$ & 0 & Normal & $46 / 51$ & 0.792223807 & IPF & $32 / 28$ & 0.543860737 & IPF/UIP \\
\hline $27 / 26$ & 0 & Normal & $3 / 50$ & 0.853712645 & Severe IF & $11 / 12$ & 0.609837285 & IPF/UIP \\
\hline $43 / 16$ & 0 & Normal & $39 / 43$ & 0.898132637 & IPF/UIP & $2 / 38$ & 0.689568308 & IPF/UIP \\
\hline $33 / 23$ & 0 & Normal & $30 / 17$ & 0.984128952 & IPF/UIP & $38 / 35$ & 0.870788258 & IPF/UIP \\
\hline $13 / 39$ & 0 & Mild emphysema & $58 / 15$ & 1.02457832 & Mild IF & $19 / 47$ & 1.07500215 & Mild IF \\
\hline $47 / 44$ & 0 & Normal & $54 / 34$ & 1.124896765 & IPF/UIP & $23 / 31$ & 1.246080924 & Inf/Honeycombing \\
\hline $31 / 45$ & 0 & Normal & $12 / 19$ & 1.127274982 & Severe IF & $48 / 53$ & 1.332033914 & Mild IF \\
\hline $20 / 46$ & 0 & Normal & $55 / 5$ & 1.135880134 & Mild IF & $35 / 10$ & 1.451763467 & IPF/UIP \\
\hline $28 / 49$ & 0 & Mild emphysema & $15 / 4$ & 1.19162088 & Mild IF & $16 / 21$ & 1.506947458 & IPF/UIP \\
\hline $5 / 52$ & 0 & Septal thickening & $42 / 32$ & 1.257089128 & IPF/UIP & $49 / 20$ & 1.597695503 & Mild IF \\
\hline $1 / 57$ & 0 & Normal & $45 / 18$ & 1.470515762 & IPF/UIP & $4 / 41$ & 1.698264266 & IPF/UIP \\
\hline $7 / 60$ & 0 & Normal & $36 / 33$ & 1.5500031 & IPF/UIP & $10 / 22$ & 2.0666708 & Mild IF \\
\hline $57 / 36$ & 0 & Mild emphysema & $24 / 42$ & 1.667114445 & IPF/UIP & $25 / 40$ & 2.214 .290 & IPF/UIP \\
\hline $14 / 3$ & 0.077500155 & A telectasis/thickening & $37 / 30$ & 2.258029207 & IPF/UIP & $21 / 37$ & 2.188697845 & Mild IF \\
\hline $8 / 27$ & 0.116043013 & Normal & $18 / 2$ & 2.294004588 & DIFFUSEIF & $56 / 24$ & 2.279055942 & IPF/UIP \\
\hline \multirow[t]{2}{*}{$41 / 14$} & 0.41333416 & Normal & $44 / 56$ & 2.679444431 & IPF/UIP & $17 / 48$ & 2.605680887 & IPF/UIP \\
\hline & & & $59 / 58$ & 3.620364384 & IPF/UIP & & & \\
\hline avg & 0.031940912 & & avg & 1.366149591 & & avg & 1.267217264 & \\
\hline stdev & 0.097448895 & & stdev & 0.808903868 & & stdev & 0.71592836 & \\
\hline
\end{tabular}

Legend: IF - interstitial fibrosis; IPF - idiopathic pulmonary fibrosis; UIP - usual interstitial pneumonia.

\section{Statistical analysis}

Comparisons of the descriptive statistics of reactive sites were made using Analysis of Variance or Kruskal-Wallis non-parametric test for histologic locations in the same reactive site groups and within lung capacity category using SAS software (Cary, NC) or Minitab (Six Sigma, State College, PA). For example, for patients in FVC 50$80 \%$, comparisons were made for reactive sites $>100$ $\left(\mu \mathrm{m}^{2}\right)$ for EF, SE, and I locations. Statistical significance was set at an alpha value of $\leq 0.05$.

\section{Results}

Lungs with normal pulmonary architecture (group 1) had weak to moderate Wnt7B immunoreactivity in the cytoplasm of airway epithelium (ciliated cells) and smooth muscle of airways and arteries (Figure 1a and inset). Much weaker Wnt7B reactivity was evident in the cytoplasm of AT2 cells (Figure 1a inset), alveolar macrophages, and endothelial cells. Lungs originally categorized with ILD and UIP/IPF (by the LTRC) had intense and discrete immunoreactive sites for Wnt7B that varied in size and location. The largest sites correlated directly with easily identifiable fibroblastic foci characteristic of
IPF, where staining was particularly intense in the extracellular matrix (Figures 1b, 1e, 2b, 2c, 2e). All sites, regardless of size and location, were unreactive with normal goat serum controls (Figure 1c). Pretreatment of sections with $5 \%$ hyaluronidase prior to immunostaining for Wnt7B completely attenuated the intense extracellular matrix reactive sites seen in parallel sections, while most cellular reactivity was retained and somewhat intensified (Figure 1d). This was particularly true of smooth muscle cells (data not shown). This increased cellular staining is likely due to the antibody detection of intracellular and cell surface-associated forms of the antigen, which is glycosylated [25], and made more available by the digestion procedure.

Simultaneous treatment of sections with Wnt7B antibody and its competitive binding Wnt7B peptide during the staining procedure resulted in significant reduction in all reactive sites in parallel sections, particularly in sites with the most intense immunoreactivity (Figure 1e vs. 1f), confirming the specificity of the staining.

Even at lower magnifications, the $\mathrm{Wnt7B}$ reactive sites were readily detectable, especially the fibroblastic foci 

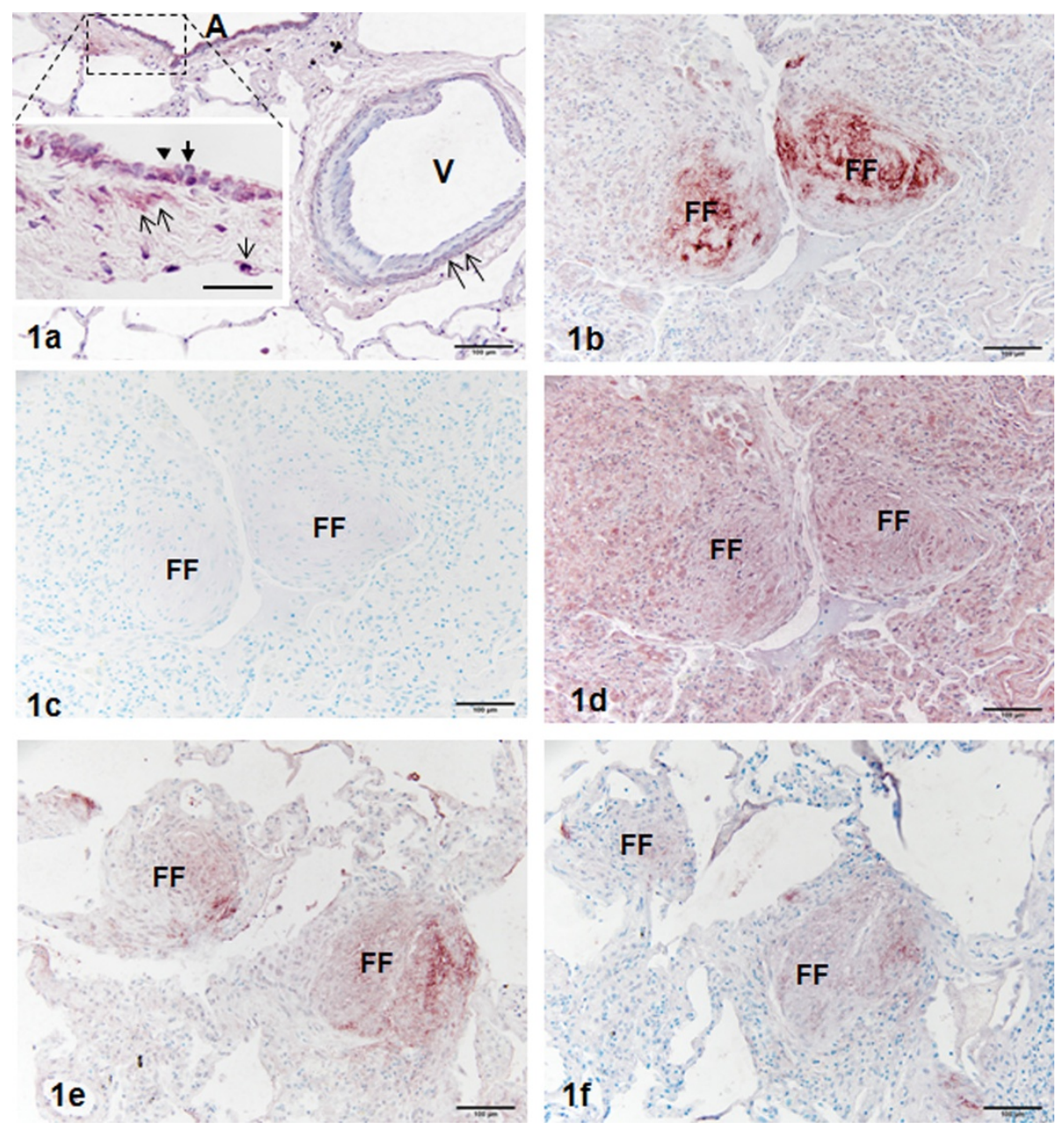

Figure 1 Section of normal human lung treated for the immunohistochemical localization of Wnt7B. Figure 1a at low power, airway (A) epithelial cells and smooth muscle (double arrows) surrounding a nearby vessel $(V$ exhibit reactivity for Wnt7B. Inset of the airway shows Wnt7B reactivity in ciliated cells (solid arrowtip), AT2 cell (single arrow), and smooth muscle (double arrows). The airway insert also shows and nonreactive non-ciliated bronchiolar cell (solid arrowhead). Methylene blue counterstain. Bar $=100 \mu \mathrm{m}$; inset Bar $=30 \mu \mathrm{m}$. Figure 1b, Section of UIP/ IPF lung treated for the immunohistochemical localization of Wnt7B. Two large fibroblastic foci (FF) demonstrate strong extracellular reactivity. Bar $=100 \mu \mathrm{m}$. Figure 1c, Serial section of UIP/IPF lung in Figure 1b treated with non-immune serum instead of the Wnt7B-specific antibody. Fibroblastic foci (FF) lack selective staining for the antigen, but show light metachromasia with the methylene blue counterstain. Bar $=100 \mu \mathrm{m}$. Figure 1d, Serial section of UIP/IPF lung in Figure 1b treated for the immunohistochemical localization of Wnt7B after being exposed for 30 minutes to hyaluronidase digestion. The same fibroblastic foci (FF) have lost the strong, extracellular reactivity seen in Figure 1b, while there is enhanced cellular reactivity throughout the tissue, presumptively due to unmasking of intracellular, glycosylated Wnt7B. Methylene blue counterstain. Bar $=100 \mu \mathrm{m}$. Figure 1e-f, Serial sections of UIP/IPF lung treated for the immunohistochemical localization of Wnt7B; the first (e) without and second (f) with the antigenic blocking peptide simultaneously with the Wnt7B-specific antibody. The two positive fibroblastic foci (FF) in (e) show diminished selective staining for Wht7B in ( $)$. Methylene blue counterstain. Bar $=100 \mu \mathrm{m}$.

(Figure 2a). Reactive sites were consistently found in one of three regional dispositions according to the criteria described above: EF, SE (which included most fibroblastic foci), and I (Figure 2b). Sequential and nonsequential serial sections were used to compare Wnt7B stained slides with those stained with H\&E, picrosirius red (PSR), Movat's pentachrome, or immunohistochemistry for smooth muscle actin. Fibroblastic foci were easily detected by their large size (typically $>100 \mu \mathrm{m}^{2)}$ and strong extracellular reactivity for Wnt7B, with most found adjacent to thickened airways (Figure 2b-c) and thickened interstitium in alveolar regions (1e, 2e). They correlated well with sequential/non-sequential serial sections stained with H\&E (data not shown) and pentachrome (2d, 2f). The red reactivity of collagen with PSR was very strong throughout IPF lungs, especially in highly thickened areas of mature collagen and thickened basal laminae (data not shown). Fibroblastic foci were easily identifiable, mainly by virtue of their lighter staining, immature collagen content (as shown with the 

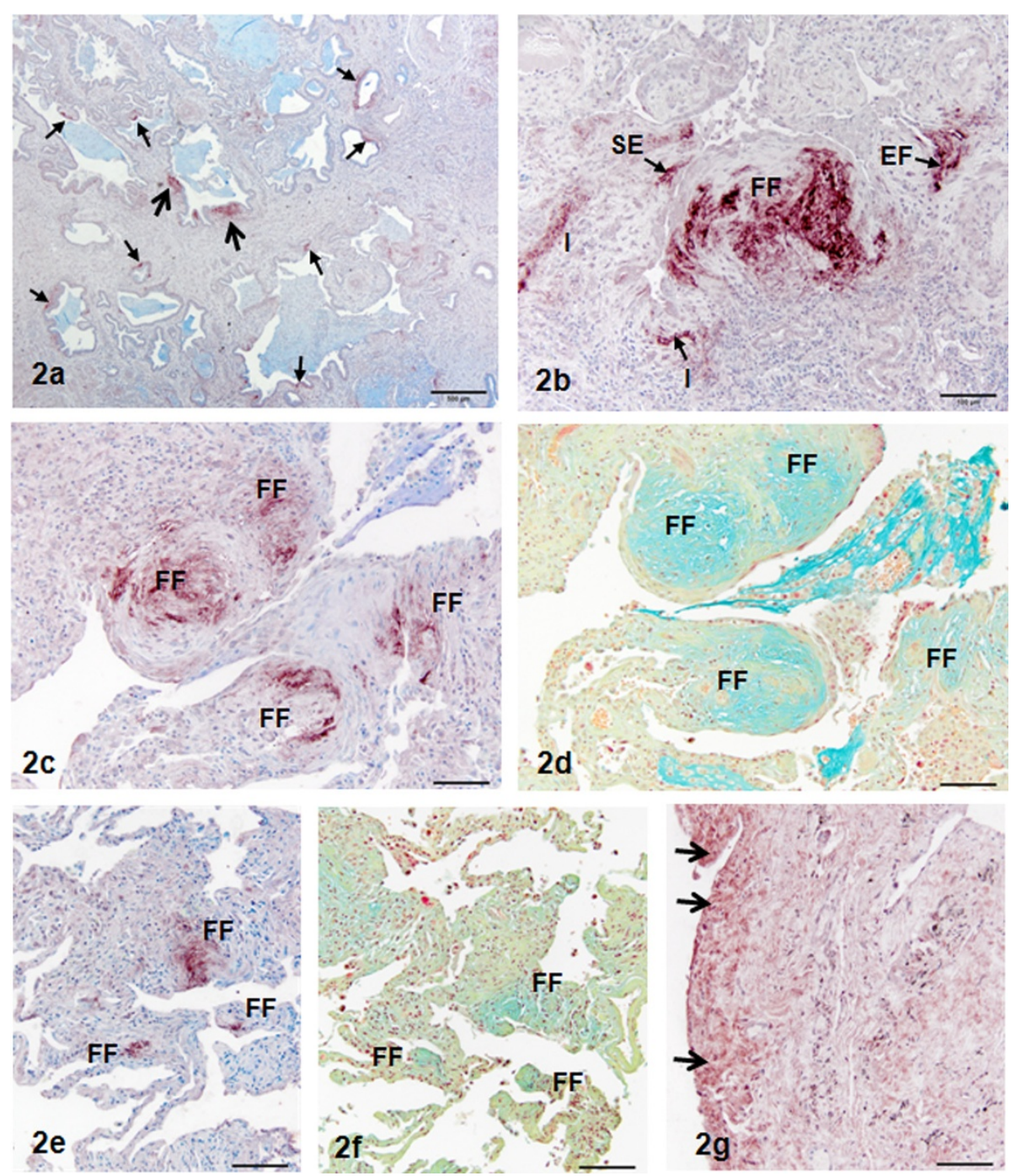

Figure 2 Low power magnification of a section of UIP/IPF lung treated for the immunohistochemical localization of Wnt7B. Fibroblastic foci are easy to identify (large arrows), as are even small reactive sites (small arrows). Methylene blue counterstain. Bar $=600 \mu \mathrm{m}$. Figure $2 \mathbf{b}$, Section of UIP/IPF lung treated for the immunohistochemical localization of Wnt7B demonstrating the three categories designated for sizing and quantitation. Preliminary histopathologic evaluation of the slides determined that all reactive sites were confined to one of three characteristic types: epithelial + fibroblast + extracellular matrix (EF), subepithelial (SE, fibroblast + extracellular matrix), or interstitial (I, not adjacent to epithelial surfaces). Methylene blue counterstain. Bar $=100 \mu \mathrm{m}$. Figure $2 \mathbf{c}-\mathbf{f}$, Serial sections of UIP/IPF lung treated for the immunohistochemical localization of Wnt7B ( $c$, e) or Movat's pentachrome $(d, f)$ in airway $(c, d)$ and alveolar (e. $f$ ) regions. The same fibroblastic foci (FF) stain clearly with both treatments. Methylene blue counterstain. Bar $=100 \mu \mathrm{m}$. Figure $2 \mathrm{~g}$, Section of UIP/IPF lung treated for the immunohistochemical localization of Wnt7B demonstrating reactivity of the mesothelial surface (arrows) and the subjacent cells and thickened interstitium. Methylene blue counterstain. Bar $=100 \mu \mathrm{m}$.

Movat's pentachrome), which gave it a finely layered appearance (data not shown).

Wnt7B immunoreactivity was found both intra- and extracellularly. Without hyaluronidase digestion, the extracellular reactivity was discrete and intense and found in the ECM regions of fibroblastic foci (Figures 1b, 1e, 2b-c, 2f), subepithelial ECM (Figure 2a$b, 3 b$ ), and interstitium (Figure $2 b$ ) not adjacent to epithelium. The sizes of the reactive sites varied widely, with fibroblastic foci having the greatest individual reactive areas (often $>1600 \mu \mathrm{m}^{2}$; Figures $1 \mathrm{~b}, 2 \mathrm{c}, 2 \mathrm{~b}-\mathrm{c}$, $2 \mathrm{e})$ and the SE regions being the most numerous and smallest in individual reactive area (Figure 2b, 3a-d). These smaller sites were not distinguishable by any morphologic features or special staining characteristics (data not shown). Intracellular reactivity was very intense in some epithelia, especially that considered hyper- or metaplastic (Figure 3a), and in fibroblasts of fibroblastic foci, especially the larger SE sites (Figure 3c) and smaller SE sites (Figure 3d). In airways, basal cells were often 

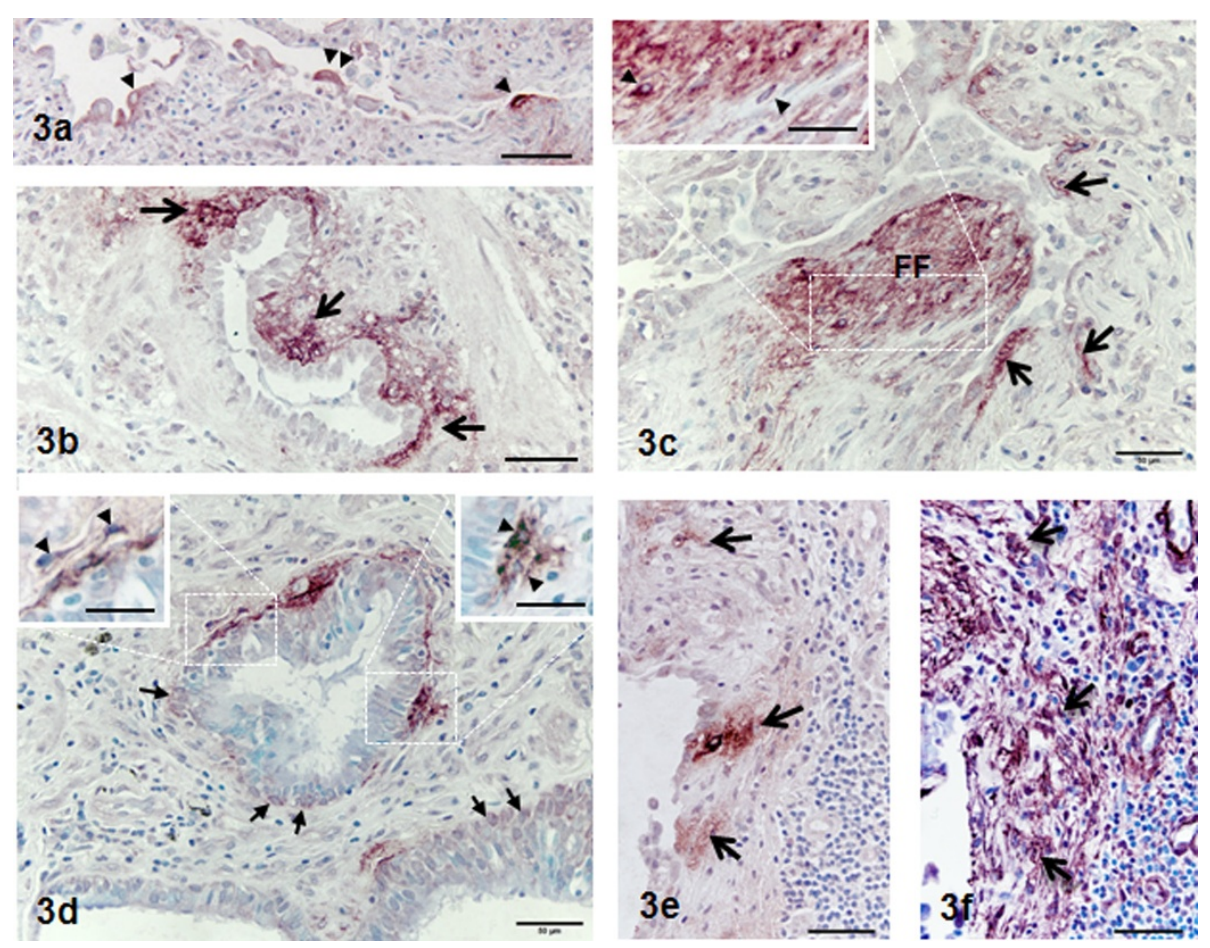

Figure 3 Sections of UIP/IPF lung treated for the immunohistochemical localization of Wnt7B. Figure 3a demonstrates staining of hypertrophic/metaplastic alveolar epithelial cells. Figure $3 \mathbf{b}$ demonstrates extensive subepithelial (SE, not an FF) site reactivity (arrows) around one side of a small airway. Figure $3 \mathbf{c}$ demonstrates reactivity within a fibroblastic focus (FF) and adjacent SE sites (arrows). The inset at higher magnification of the fibroblastic foci demonstrates the extracellular matrix and cellular (arrow) nature of the reactivity. Figure 3d demonstrates extensive subepithelial (SE) site reactivity (arrows) around two small airways, the apparent reactivity of presumptive basal cells (arrows) within the respective airways. The inset at higher magnification shows presumptive, reactive fibroblasts embedded within reactive matrix (arrowheads). Methylene blue counterstain. Bars $=50 \mu \mathrm{m}$; inset bars $=30 \mu \mathrm{m}$.

reactive (Figure 3d), as were some ciliated cells (data not shown). Mesothelium was generally positive, but mesothelial immunoreactivity was most intense when overlying areas of interstitial fibrosis (Figure 2g). Macrophages were variably reactive for Wnt7B, while other inflammatory cells present in IPF/UIP lungs were uniformly negative (data not shown). Many SE sites reflected staining of portions of basal lamina (Figures 3b-d) and/or strong staining of fibroblasts within the subepithelial fibroblast layer (Figure 3d). The fibroblastic component of Wnt7Bpositive fibroblastic foci (Figure 3d-e) was uniformly positive for smooth muscle actin (Figure 3f), reflective of the myofibroblast phenotype.

Patients with FVC $>80 \%$ had few quantifiable Wnt7B reactive sites (Figure 4a) compared to patients with functional diagnoses of IPF/UIP $[<80 \%$ (Figures $4 \mathrm{~b}-\mathrm{c}$ )]. There were insufficient reactive sites for the EF category to compare to corresponding reactive SE and I regions. Despite an outlier (defined as greater than 2 standard deviations from the mean) for the SE region $<50 \mu \mathrm{m}^{2}$ category, the reactive sites for locations SE and I were not statistically different, given that the median value was 0 for all reactive sites by location. For patients with
FVC $50-80 \%$ and FVC $<50 \%$, reactive site size means (in $\mu \mathrm{m}^{2}$ ), standard deviations, and minimum, median, and maximum sizes of reactive sites $\left(\right.$ in $\mu \mathrm{m}^{2}$ ) are presented in Tables 2 and 3. For patients with FVC $50-80 \%$ and FVC $<50 \%$, the means of the number of each of the reactive site sizes for the SE location were statistically greater than that of those for EF and I locations $(\mathrm{p}<0.05)$.

\section{Discussion}

The initiating cause(s) underlying the pathogenesis of idiopathic pulmonary fibrosis (IPF) is unknown. Much attention has focused on a failed repair of alveolar epithelium, and its impact on subsequent loss of pulmonary architecture. This failure manifests as the inability of epithelial surfaces to proliferate and differentiate effectively resulting in hyperplasia, metaplasia, and/or transdifferentiation into myofibroblast-like cells [26]. Exactly how these dysplastic events culminate, independently or collectively, in the formation of one of the hallmarks of IPF, the fibroblastic focus, is not clear. Studying the roles that specific signaling pathways play in the complex processes involved in the formation of fibroblastic foci has 


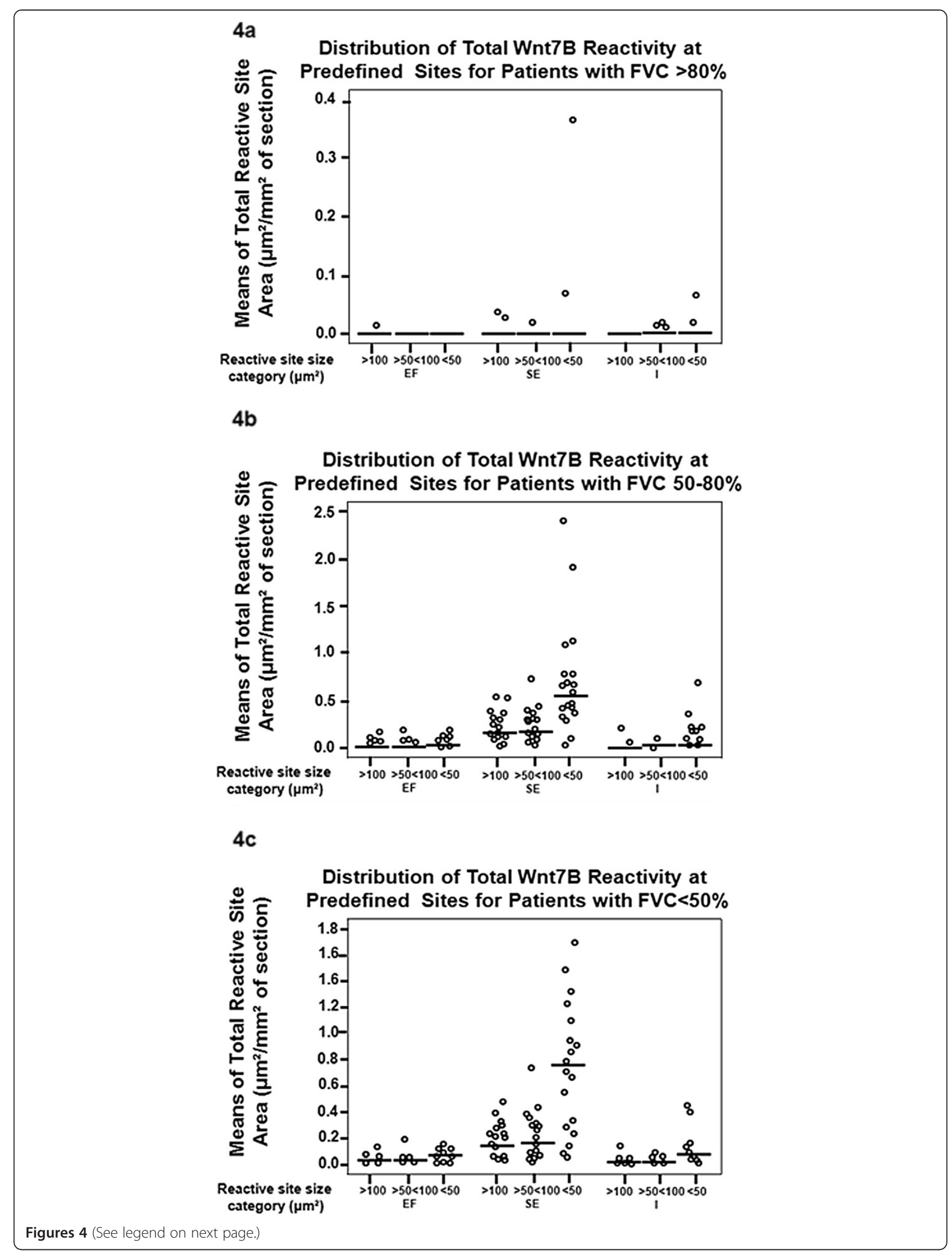


(See figure on previous page.)

Figures 4 Distribution of the total Wnt7B reactivity at the EF, SE, and I site categories for patients with FVCs $>\mathbf{8 0} \%$ (normal), 50-80\% (intermediate impairment), or $<\mathbf{5 0} \%$ (severe impairment). Normal patients had minimal Wnt7B reactivity, most with a median total area reactivity of " 0 " (a). Patients with impaired FVCs had many more reactive sites than controls, although those with intermediate and severe impairment were not different (see Tables 2 and 3). Notably, the median of the mean total of reactivity was greatest in the SE sites that were $<50 \mu \mathrm{m}^{2}$ (b-c).

led to a greater understanding of important growth factors, such as TGF- $\beta$, that not only promote the deposition of excessive collagen but mediate the process of EMT as well [10]. TGF- $\beta$ has been immunohistochemically localized to alveolar epithelium and extracellular matrix of IPF lungs [27] and is within fibroblastic foci $[28,29]$. Fibroblastic foci are also rich in its downstream nuclear targets like phospho-Smad 2/3 [28] and relevant proteins, such as cysteine-rich protein 1 (CRP-1), which is important in smooth muscle cell differentiation [30]. Relatedly, activated $\beta$-catenin has been shown to be upregulated in the nuclei of myofibroblasts of fibroblastic foci of IPF patients [14], and alveolar epithelial responses to TGF- $\beta$ involve alpha3 integrin for $\beta$-catenin phosphorylation and formation of a $\beta$-catenin $/ \mathrm{p}-\mathrm{Smad} 2 \mathrm{com}$ plex resulting in initiation of EMT [31]. More specifically, TGF- $\beta$-stimulated Smad3 has recently been shown to form a complex with $\beta$-catenin and CREBbinding protein in regulation of $\alpha$-smooth muscle actin, a cytologic signature of EMT [32]. SPARC (secreted protein acidic rich in cysteine), an extracellular matrix component abundant in fibroblastic foci [33], should also be noted, as it has been shown to activate AKT, inhibit GSK-3 $\beta$, and activate $\beta$-catenin, resulting in an antiapoptotic phenotype [34], another characteristic of the IPF myofibroblast. [10-12].

The finding of strong Wnt7B immunoreactivity in the fibroblastic focus of UIP/IPF lungs would seem to fit readily with the above discussion on canonical Wnt signaling involving $\beta$-catenin. The demonstration of Wnt7B in dysplastic airway and alveolar epithelium and in myofibroblasts of the fibroblastic foci closely correlates with

Table 2 Patients with FVC $>\mathbf{5 0} \%<\mathbf{8 0} \%$

\begin{tabular}{llllll}
\hline Site $/$ size & Mean & StDev & Min & Med & Max \\
\hline$E F>100$ & 0.02098 & 0.03446 & 0 & 0.00906 & 0.14388 \\
$E F>50<100$ & 0.01925 & 0.03713 & 0 & 0.00829 & 0.17004 \\
$E F<50$ & 0.0427 & 0.0477 & 0 & 0.0181 & 0.1653 \\
SE $>\mathbf{1 0 0}$ & ${ }^{*} \mathbf{0 . 1 9 8}$ & $\mathbf{0 . 1 5 0 8}$ & $\mathbf{0}$ & $\mathbf{0 . 1 6 1 3}$ & $\mathbf{0 . 5 1 6 7}$ \\
SE $>\mathbf{5 0}<\mathbf{1 0 0}$ & ${ }^{*} \mathbf{0 . 1 9 4}$ & $\mathbf{0 . 1 7 1 5}$ & $\mathbf{0}$ & $\mathbf{0 . 1 5 7 5}$ & $\mathbf{0 . 7 0 8 6}$ \\
SE $<\mathbf{5 0}$ & ${ }^{*} \mathbf{0 . 6 7 5}$ & $\mathbf{0 . 5 6 2}$ & $\mathbf{0}$ & $\mathbf{0 . 5 3 7}$ & $\mathbf{2 . 3 8}$ \\
$\mid>100$ & 0.02319 & 0.04121 & 0 & 0.00829 & 0.186 \\
$\mid>50<100$ & 0.0231 & 0.02473 & 0 & 0.01027 & 0.08267 \\
$\mid<50$ & 0.1044 & 0.152 & 0 & 0.0458 & 0.6613 \\
\hline
\end{tabular}

the site localization of active $\beta$-catenin in IPF lungs [14]. However, that study did not report active $\beta$-catenin in fibroblasts/myofibroblasts in regions other than fibroblastic foci. Wnt7B localization, demonstrated here, was also clearly defined in a large number of smaller sites $\left(<50 \mu \mathrm{m}^{2}\right)$ that, like fibroblastic foci, had both cellular and extracellular matrix components. The loss of extracellular Wnt7B immunoreactivity after hyaluronidase digestion supports the matrix-associated localization, which is not surprising, as Reichsman, et al., [24] have demonstrated that most secreted Wnts (approximately $83 \%$ ) are bound to the cell surface and surrounding extracellular matrix through specific, non-covalent interactions. The localization of Wnt7B in fibroblastic foci and a large number of smaller subepithelial sites position it well for influencing the activity of the underlying interstitium. In normal lung development, murine Wnt7b has been shown to be exclusively expressed in epithelial cells and regulated by TTF-1, GATA-6, and FoxA2 [35]. In the embryo, it has been demonstrated to stimulate epithelial and mesenchymal proliferation, likely through its activation of BMP-4 and Id2 [36]. Further, $\mathrm{Wnt} 7 \mathrm{~b} / \beta$-catenin signaling regulates a program of mesenchymal cell differentiation and proliferation that is necessary for smooth muscle cell development in cooperation with tenascin-C and involving PDGFR-alpha and PDGFR-beta [37]. It may not be surprising, then, that similar genetic programs are reactivated in some form in an adult disease such as IPF, in which tenascin$\mathrm{C}$ is heavily expressed in the matrix of fibroblastic foci

Table 3 Patients with FVC $<\mathbf{5 0 \%}$

\begin{tabular}{llllll}
\hline Site/size & Mean & StDev & \multicolumn{1}{c}{ Min } & Med & \multicolumn{1}{c}{ Max } \\
\hline$E F>100$ & 0.02615 & 0.02849 & 0 & 0.0159 & 0.10568 \\
EF $>50<100$ & 1.02039 & 0.02286 & 0 & 0.01761 & 0.07789 \\
EF $<50$ & 0.04478 & 0.03933 & 0 & 0.04559 & 0.124 \\
SE $>\mathbf{1 0 0}$ & $* \mathbf{0 . 1 5 8 9}$ & $\mathbf{0 . 0 3 9 3 3}$ & $\mathbf{0 . 0 0 6 7 7}$ & $\mathbf{0 . 1 3 1}$ & $\mathbf{0 . 4 5 2 4}$ \\
SE $>\mathbf{5 0}<\mathbf{1 0 0}$ & $* \mathbf{0 . 2 1 2 1}$ & $\mathbf{0 . 1 6 7}$ & $\mathbf{0 . 0 1 2 4}$ & $\mathbf{0 . 1 9 7 6}$ & $\mathbf{0 . 6 2 2 8}$ \\
SE $<\mathbf{5 0}$ & $* \mathbf{0 . 7 1 7 0}$ & $\mathbf{0 . 4 7 7}$ & $\mathbf{0 . 0 3 5 2}$ & $\mathbf{0 . 7 5 5}$ & $\mathbf{1 . 6 5 4}$ \\
I $>100$ & 0.01564 & 0.02594 & 0 & 0.0124 & 0.11683 \\
I $>50<100$ & 0.02883 & 0.03709 & 0 & 0.02067 & 0.15578 \\
I $<50$ & 0.093 & 0.1135 & 0 & 0.0671 & 0.4284 \\
\hline
\end{tabular}

* the means of the number of each of the reactive site sizes for the SE location were statistically greater than that of those for EF and I locations $(p<0.05)$. 
[33] where myofibroblasts expressing PDGFRs are located [38]. Coupled with the strong expression of Wnt7B in hyperplastic/metaplastic epithelium and fibroblastic foci reported here, these observations support previous conclusions that epithelium in IPF may be responsible for aberrant activation of Wnt signaling, such as that of Wnt7B, in adjacent mesenchyme, leading to damage to the lung and fibrosis [19].

The notion that Wnt7B may have a potentially contributive if not significant role in the development and/ or progression of IPF draws on previous assumptions that the fibroblastic foci are central to the disease process and its prognosis $[39,40]$. The fibroblastic foci were the most dramatic sites of Wnt7B localization observed in the IPF lung specimens. However, when systematically categorized and analyzed relative to location and size, the Wnt7B reactive sites of large fibroblastic foci were not the most numerous nor did they consume the greatest percentage of total tissue section area, regardless of disease severity according to \% FVC, assuming the section samples correctly reflected the overall extent of fibrotic change of the whole lung (see Figure 4). This distinction belonged to the small subepithelial (SE) sites $<50 \mu^{2}$ (Figures 1d, 2a, 3b-d). These unique reactive sites had no other morphological features that were specifically distinguishing other than their discrete Wnt7B immunoreactivity. In parallel sections, the small SE sites, like the larger fibroblastic foci, consistently contained abundant cells expressing the myofibroblast phenotype, as indicated by $\alpha$-smooth muscle actin immunoreactivity (Figure 3f), but by virtue of their Wnt7B reactivity, clearly represented a subpopulation of these cells compared with the overall total myofibroblast population in IPF lungs. While it is not clear from the current data that there are any connections between the Wnt7B positive reactivity of the fibroblastic foci and the more numerous, smaller SE sites, Cool, et al., [41] demonstrated with three-dimensional reconstruction of pentachrome-stained sections that fibroblastic foci of UIP form a complex, interconnected network that extends from the pleura into the parenchyma. Perhaps the strong reactivity for Wnt7B within fibroblastic foci, shown here to correlate precisely with pentachrome reactivity, along with the foci's complement of established pro-fibrogenic components constitute the expansion unit of IPF, and the small Wnt7B-positive, subepithelial (SE) sites are the leading edge of this process. The location of the small SE sites could portend the epithelialfibroblast cross-talk often involving Wnt signaling and known to be important determinants of the fibrogenic events characteristic of IPF [26]. The regionally confined localization of Wnt7B differs from that of Wnt5A, which is strongly expressed in the majority of fibroblasts derived from UIP patients (i.e., almost all of the remaining fibroblasts), and shown to signal through non-canonical pathways, promote proliferation, and prevent apoptosis [42]. It raises the possibility that Wnt7B and Wnt5A, along with TGF- $\beta$, SPARC, and tenascin-C, work in some coordinated or concerted fashion to modulate fibroblast/myofibroblast activities in adjacent and/or different anatomic regions of IPF lungs. Extensive and more detailed studies are currently underway to help develop a better understanding of this complex process.

\section{Conclusions}

These observations draw attention to a specific Wnt signaling ligand, Wnt7B, which by virtue of its established roles in epithelial and mesenchymal proliferation and differentiation, procollagen production, and enhanced gene expression in IPF, would be expected to act as a significant contributor to the pathogenesis of IPF. This is supported not only by the strong expression of Wnt7B in fibroblastic foci but also by the numerous, small subepithelial sites that may represent early stages of developing fibroblastic foci as part of a larger, expanding network of fibrogenic tissue.

\section{Competing interests}

There are no competing interests to report by any of the authors.

\section{Authors' contributions}

TM - performed immunostaining, prepared photographic images, drafting and revision of manuscript; $\mathrm{AH}$ - performed immunostaining, $\mathrm{KF}$ developed protocol staining and performed immunostaining; BG performed immunostaining; JT - developed immunostainig protocol; DN interpretation of data, drafting and revision of manuscript; SJ - analysis and interpretation of data, manuscript revision; MC - analysis and interpretation of data, statistical analysis; PS - conception and design of study, analysis and interpretation of data, preparation of photographic images, drafting of manuscript and revision; all authors read and approved of the final manuscript.

\section{Aknowledgments}

This investigation was supported by PHS grants HL44497, HL95411, North Carolina State University College of Veterinary Medicine, and the State of North Carolina. The authors wish to thank Thomas Sporn, M.D., Department of Pathology, Duke University Medical Center, Durham, NC, for his guidance and diagnostic support, and Laura Shewmon, Department of Population Health and Pathology, College of Veterinary Medicine, North Carolina State University for her technical contribution to this study.

\section{Author details}

'Departments of Molecular Biomedical Sciences, College of Veterinary Medicine, North Carolina State University, 1060 William Moore Dr, Raleigh, NC 27607, USA. ${ }^{2}$ Population Health and Pathology, enter for Comparative Medicine and Translational Research, College of Veterinary Medicine, North Carolina State University, Raleigh, NC, USA.

Received: 25 May 2012 Accepted: 17 July 2012

Published: 28 July 2012

\section{References}

1. Green FH: Overview of pulmonary fibrosis. Chest 2002, 122:334S-339S.

2. Schwartz DA, Helmers RA, Galvin JR, Van Fossen DS, Frees KL, Dayton CS, Burmeister LF, Hunninghake GW: Determinants of survival in idiopathic pulmonary fibrosis. Am J Respir Crit Care Med 1994, 149:450-454. 
3. Strieter RM: Con: Inflammatory mechanisms are not a minor component of the pathogenesis of idiopathic pulmonary fibrosis. Am J Respir Crit Care Med 2002, 165:1206-1207. discussion 1207-8.

4. Strieter RM: Pathogenesis and natural history of usual interstitial pneumonia: the whole story or the last chapter of a long novel. Chest 2005, 128:526S-532S

5. Konigshoff M, Eickelberg O: WNT signaling in lung disease: a failure or a regeneration signal? Am J Respir Cell Mol Biol 2010, 42:21-31.

6. Katzenstein AL, Myers $\mathrm{J}$ : Idiopathic pulmonary fibrosis: clinical relevance of pathologic classification. Am J Respir Crit Care Med 1998, 157:1301-1315.

7. Katzenstein AL, Zisman DA, Litzky LA, Nguyen BT, Kotloff RM: Usual interstitial pneumonia: histologic study of biopsy and explant specimens. Am J Surg Pathol 2002, 26:1567-1577.

8. Kapanci Y, Desmouliere A: Pache JC, Redard M. Gabbiani G: Cytoskeletal protein modulation in pulmonary alveolar myofibroblasts during idiopathic pulmonary fibrosis. Possible role of transforming growth factor beta and tumor necrosis factor alpha. Am J Respir Crit Care Med 1995, 152:2163-2169.

9. Adamson IY, Hedgecock C, Bowden DH: Epithelial cell-fibroblast interactions in lung injury and repair. Am J Pathol 1990, 137:385-392.

10. Broekelmann TJ, Limper AH, Colby TV, McDonald JA: Transforming growth factor beta 1 is present at sites of extracellular matrix gene expression in human pulmonary fibrosis. Proc Natl Acad Sci USA 1991, 88:6642-6646.

11. Scotton CJ, Chambers RC: Molecular targets in pulmonary fibrosis: the myofibroblast in focus. Chest 2007, 132:1311-1321.

12. Salazar KD, Lankford SM, Brody AR: Mesenchymal stem cells produce Wnt isoforms and TGF-beta1 that mediate proliferation and procollagen expression by lung fibroblasts. Am J Physiol Lung Cell Mol Physiol 2009, 297:L1002-L1011.

13. Attisano L, Labbe E: TGFbeta and Wnt pathway cross-talk. Cancer Metastasis Rev 2004, 23:53-61.

14. Chilosi M, Poletti V, Zamo A, Lestani M, Montagna L, Piccoli P, Pedron S, Bertaso M, Scarpa A, Murer B, Cancellieri A, Maestro R, Semenzato G, Doglioni C: Aberrant Wnt/beta-catenin pathway activation in idiopathic pulmonary fibrosis. Am J Pathol 2003, 162:1495-1502.

15. Douglas IS: Diaz del Valle F, Winn RA, Voelkel NF: Beta-catenin in the fibroproliferative response to acute lung injury. Am J Respir Cell Mol Biol 2006, 34:274-285.

16. Willert K, Nusse R: Beta-catenin: a key mediator of Wnt signaling Curr Opin Genet Dev 1998, 8:95-102.

17. Konigshoff M, Balsara N, Pfaff EM, Kramer M, Chrobak I, Seeger W, Eickelberg $\mathrm{O}$ : Functional Wnt signaling is increased in idiopathic pulmonary fibrosis. PLoS One 2008, 3:e2142.

18. van der Velden JL, Guala AS, Leggett SE, Sluimer J, Badura EC, Janssen-Heininger YM: Induction of a Mesenchymal Expression Program in Lung Epithelial Cells by Wnt/beta-catenin Requires the Presence of c-Jun N-Terminal Kinase 1. Am J Respir Cell Mol Biol 2012, doi:10.1165/rcmb.2011-029. Published ahead of print on March 2012.

19. Morrisey EE: Wnt signaling and pulmonary fibrosis. Am J Pathol 2003 162:1393-1397.

20. Winn RA, Marek L, Han SY, Rodriguez K, Rodriguez N, Hammond M, Van Scoyk M, Acosta H, Mirus J, Barry N, Bren-Mattison Y, Van Raay TJ, Nemenoff RA, Heasley LE: Restoration of Wnt-7a expression reverses non-small cell lung cancer cellular transformation through frizzled-9-mediated growth inhibition and promotion of cell differentiation. J Biol Chem 2005, 280:19625-19634.

21. Apparao KB, Newman DR, Zhang H, Khosla J, Randell SH, Sannes PL: Temporal changes in expression of FoxA1 and Wnt7A in isolated adult human alveolar epithelial cells enhanced by heparin. Anat Rec (Hoboken) 2010, 293:938-946

22. He W, Dai C, Li Y, Zeng G, Monga SP, Liu Y: Wnt/beta-catenin signaling promotes renal interstitial fibrosis. J Am Soc Nephrol 2009, 20:765-776.

23. Shu W, Jiang YQ, Lu MM, Morrisey EE: Wnt7b regulates mesenchymal proliferation and vascular development in the lung. Development 2002, 129:4831-4842

24. Reichsman F, Smith L, Cumberledge S: Glycosaminoglycans can modulate extracellular localization of the wingless protein and promote signal transduction. J Cell Biol 1996, 135:819-827.

25. Smolich BD, McMahon JA, McMahon AP, Papkoff J: Wnt family proteins are secreted and associated with the cell surface. Mol Biol Cell 1993, 4:1267-1275.
26. Coward WR, Saini G, Jenkins G: The pathogenesis of idiopathic pulmonary fibrosis. Ther Adv Respir Dis 2010, 4:367-388.

27. Khalil N, O'Connor RN, Flanders KC, Unruh H: TGF-beta 1, but not TGF-beta 2 or TGF-beta 3, is differentially present in epithelial cells of advanced pulmonary fibrosis: an immunohistochemical study. Am J Respir Cell Mol Biol 1996, 14:131-138.

28. Jonigk D, Theophile K, Hussein K, Bock O, Lehmann U, Bockmeyer CL, Gottlieb J, Fischer S, Simon A, Welte T, Maegel L, Kreipe H, Laenger F: Obliterative airway remodelling in transplanted and non-transplanted lungs. Virchows Arch 2010, 457:369-380.

29. Lomas NJ, Watts KL, Akram KM, Forsyth NR, Spiteri MA: Idiopathic pulmonary fibrosis: immunohistochemical analysis provides fresh insights into lung tissue remodelling with implications for novel prognostic markers. Int J Clin Exp Pathol 2012, 5:58-71.

30. Jarvinen PM, Myllarniemi M, Liu H, Moore HM, Lepparanta O, Salmenkivi K, Koli K, Latonen L, Band A, Laiho M: Cysteine-rich protein 1 is regulated by transforming growth factor-beta 1 and expressed in lung fibrosis. J Cell Physiol 2011, 227(6):2605-2612.

31. Kim KK, Wei Y, Szekeres C, Kugler MC, Wolters PJ, Hill ML, Frank JA Brumwell AN, Wheeler SE, Kreidberg JA, Chapman HA: Epithelial cell alpha3beta1 integrin links beta-catenin and Smad signaling to promote myofibroblast formation and pulmonary fibrosis. J Clin Invest 2009, 119:213-224.

32. Zhou B, Liu Y, Kahn M, Ann DK, Han A, Wang H, Nguyen C, Flodby P, Zhong Q, Krishnaveni MS, Liebler JM, Minoo P, Crandall ED, Borok Z: beta-g. J Biol Chem 2012, 2012:2012-2012.

33. Kuhn C, Mason RJ: Immunolocalization of SPARC, tenascin, and thrombospondin in pulmonary fibrosis. Am J Pathol 1995, 147:1759-1769.

34. Chang W, Wei K, Jacobs SS, Upadhyay D, Weill D, Rosen GD: SPARC suppresses apoptosis of idiopathic pulmonary fibrosis fibroblasts through constitutive activation of beta-catenin. J Biol Chem 2010, 285:8196-8206.

35. Weidenfeld J, Shu W, Zhang L, Millar SE, Morrisey EE: The WNT7b promoter is regulated by TTF-1, GATA6, and Foxa2 in lung epithelium. $J$ Biol Chem 2002, 277:21061-21070.

36. Rajagopal J, Carroll TJ, Guseh JS, Bores SA, Blank LJ, Anderson WJ, Yu J, Zhou Q, McMahon AP, Melton DA: Wnt7b stimulates embryonic lung growth by coordinately increasing the replication of epithelium and mesenchyme. Development 2008, 135:1625-1634.

37. Cohen ED, Ihida-Stansbury K, Lu MM, Panettieri RA, Jones PL, Morrisey EE: Wnt signaling regulates smooth muscle precursor development in the mouse lung via a tenascin C/PDGFR pathway. J Clin Invest 2009, 119:2538-2549.

38. Vuorinen K, Ohlmeier S, Lepparanta O, Salmenkivi K, Myllarniemi M, Kinnula $V L$ : Peroxiredoxin II expression and its association with oxidative stress and cell proliferation in human idiopathic pulmonary fibrosis. J Histochem Cytochem 2008, 56:951-959.

39. Enomoto N, Suda T, Kato M, Kaida Y, Nakamura Y, Imokawa S, Ida M, Chida K: Quantitative analysis of fibroblastic foci in usual interstitial pneumonia. Chest 2006, 130:22-29.

40. Flaherty KR, Colby TV, Travis WD, Toews GB, Mumford J, Murray S, Thannickal VJ, Kazerooni EA, Gross BH, Lynch JP 3rd, Martinez FJ: Fibroblastic foci in usual interstitial pneumonia: idiopathic versus collagen vascular disease. Am J Respir Crit Care Med 2003, 167:1410-1415.

41. Cool CD, Groshong SD, Rai PR, Henson PM, Stewart JS, Brown KK: Fibroblast foci are not discrete sites of lung injury or repair: the fibroblast reticulum. Am J Respir Crit Care Med 2006, 174:654-658.

42. Vuga LJ, Ben-Yehudah A, Kovkarova-Naumovski E, Oriss T, Gibson KF Feghali-Bostwick C, Kaminski N: WNT5A is a regulator of fibroblast proliferation and resistance to apoptosis. Am J Respir Cell Mol Biol 2009, 41:583-589.

doi:10.1186/1465-9921-13-62

Cite this article as: Meuten et al:: WNT7B in fibroblastic foci of idiopathic pulmonary fibrosis. Respiratory Research 2012 13:62. 